\title{
A Construção do Porto do Rio de Janeiro e a Caixa Especial dos Portos: reordenamento territorial e desenvolvimento
}

\section{The Construction of the Port of Rio de Janeiro and the Caixa Especial dos Portos: Territorial Reordering and Development}

\author{
Cezar Honorato ${ }^{1,}$ * (iD 0000-0003-4212-7395 \\ Lucas Tavares Honorato $^{1}$ (D) 0000-0003-0422-2199
}

${ }^{1}$ Universidade Federal Fluminense, Niterói, Rio de Janeiro, Brasil.

* Correspondencia: cezarhonorato@id.uff.br

Resumo. O objetivo do presente artigo é de apresentar os primeiros resultados do Global South Project. Puertos y desarrollo económico y social en el Atlántico Meridional (1850-2010) e do Projeto Acervo Documental da Secretaria do Patrimônio da União (SPU) com o apoio de Universidade Federal Fluminense e Banco Interamericano de Desenvolvimento (UFF/BID). Neste sentido, analisamos a construção do porto do Rio de Janeiro através da Caixa Especial dos Portos e da implantação de uma nova Comunidade Econômica Portuária, no momento em que o Brasil entra definitivamente na rede global marítima. Apresentamos uma reflexão acerca das possibilidades de utilização principalmente da cartografia e dos processos administrativos como fontes devido ao fato de ser uma documentação ainda inédita, bem como uma análise da atuação da Caixa Especial dos Portos no trato com as empresas e empresários interessados na nova região portuária e seus desdobramentos.

Palavras-chave: Porto do Rio de Janeiro; Caixa Especial dos Portos; reordenamento territorial.

CÓMO CITAR: Honorato, C. T. e Honorato, L. T. (2020). A construção do Porto do Rio de Janeiro e a Caixa Especial dos Portos: reordenamento territorial e desenvolvimento. América Latina en la Historia Económica, 27(3), e1075. doi: 10.18232/alhe.1075 
Abstract. The purpose of this article is present the first results of Global South Project. Puertos y desarrollo económico y social en el Atlántico Meridional (1850-2010) and the Project Acervo Documental da spu with the support of the Fluminense Federal University and the Inter-American Development Bank (UFF/BID, Portuguese acronyms). In this sense, we analyze the construction of Port of Rio de Janeiro through the Caixa Especial dos Portos and the new Economic Ports Community, at a time when Brazil definitely enters the global maritime network. Also, we present a reflection about the possibilities of using mainly the cartography and the administrative processes as sources due to the fact that it's unprecedented documentation; as well, we analyze the performance of Caixa Especial dos Portos in the treatment of large companies installed in the new port region and its unfolding.

Key words: Port of Rio de Janeiro; Caixa Especial dos Portos; territorial reorganization.

JEL: N16; N26; N36; N96.

Recibido: 02 de abril de 2019

Aceptado: 23 de junho de 2019

Publicado: 10 de agosto de 2020.

\section{INTRODUÇÃO}

Depois de extensa pesquisa a respeito da montagem de um complexo industrial capitalista no porto de Santos nos enfocamos, dessa vez, o maior porto do país no século xix: o porto do Rio de Janeiro. Os desafios eram grandes, haja visto que o tema se encontrava relegado a segundo plano pela historiografia urbana da cidade desde os anos noventa, quando Sergio Lamarão publicou sua dissertação em 1922. Entretanto, este e outros trabalhos (Honorato e Santos, 2010) são resultado de um esforço coletivo de pesquisa que envolve pesquisadores e pesquisadoras de todo país, enga-

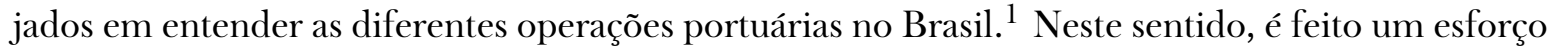
de, não só avançar teoricamente acerca do tema, mas, principalmente, para avançar na busca de fontes que também levem à reflexão sobre os impactos da construção do porto do Rio de Janeiro no início do século xx como elemento de indução de atividades econômicas.

Em Honorato e Mantuano (2016) definimos como Comunidade Econômica Portuária o conjunto de:

[...] atividades econômicas produtivas ou de serviços que vão surgindo e se consolidando como necessárias ou complementares ao funcionamento do porto, possibilitando que as mercadorias efetivamente cheguem ao seu destino com menos custo e segurança. De outra forma, o conjunto de atividades econômicas que, direta ou indiretamente, estão vinculadas às atividades portuárias e que se instalaram no seu entorno (p. 12).

De acordo com o Projeto Acervo Documental da Secretaria do Patrimônio da União (SPU), com o apoio de Universidade Federal Fluminense e Banco Interamericano de Desenvolvimento (UFF/BID), foi possível ter acesso a uma documentação ainda não explorada por outros pesquisadores, com especial destaque aos processos administrativos de desapropriação, de leilões de usu-

\footnotetext{
${ }^{1}$ Portos e Cidades no Mundo Atlântico, grupo de pesquisa registrado no Conselho Nacional de Desenvolvimento Científico e Tecnológico.
} 
fruto, de aforamentos ou de incorporação de áreas para a construção do novo porto e as várias formas de cessão destes imóveis para terceiros, além de uma inédita iconografia relacionada ao tema.

Dentre os vários fundos documentais existentes na SPU acerca do patrimônio público da União Federal, destaca-se o referente à região portuária pelo volume documental e pela importância da documentação: processos administrativos, escrituras, contratos, livros registrais/cadastrais, editais e demais documentação textual, assim como a rica documentação iconográfica, composta especialmente por plantas e mapas, assim como outras imagens. Dentre estes fundos, temos o da Caixa Especial dos Portos, criada em 1903 pelo presidente da República, Francisco de Paula Rodrigues Alves, para administrar os recursos para a construção do novo porto do Rio de Janeiro como empréstimos, arrecadação de taxas e tributos e da cessão dos terrenos desapropriados ou acrescidos com as obras do porto.

Por se tratar de uma documentação até então inédita, não seriada e com muita diversidade tipológica, consideramos a proposta apresentada por Ginsburg (1990) de utilização de indícios como forma de explorar processos administrativos complexos e que não apresentem fontes seriais. Embora ainda pouco utilizada na história econômica, o método indiciário se mostrou bastante pertinente visto a grande diversidade das fontes utilizadas combinado com recursos oriundos da ciência cartográfica e alguns dados estatísticos.

Embora a bibliografia sobre a relação entre reformas portuárias e transformações urbanas esteja entre as preocupações de vários estudiosos (por exemplo Bird, 1963, Castillo, 2015, García e Rey, 2016, Guimerá e Romero, 1996, Hayuth, 1982, Hoyle e Pinder, 1992 ou Suárez Bosa, 2014, este artigo se distingue por ser um estudo de caso, pelas fontes utilizadas, bem como, pela metodologia utilizada.

Para avançar na caracterização da Comunidade Econômica Portuária utilizando estas novas fontes, ao mesmo tempo estimular o debate acerca do impacto da construção de um porto capitalista na configuração e ordenamento territorial na região, buscamos retratar os mecanismos através dos quais foi realizada a construção da primeira seção do Porto do Rio de Janeiro, de 1903 a 1910, e a criação e o papel da Caixa Especial dos Portos como estratégia de garantia da intervenção e gestão dos recursos, e sua capacidade de criação ou ampliação da Comunidade Econômica Portuária do Rio de Janeiro e do reordenamento territorial da região ao longo das três primeiras décadas do século xx.

A meta também refletir acerca da documentação -especialmente processos e plantas- existentes nos arquivos da SPU buscando apontar a importância de sua utilização como fonte da história dos portos e cidades do Brasil, com ênfase no caso do Rio de Janeiro entre o final do século xIx e o início do xx, além como avaliar a eficácia da Caixa Especial dos Portos para o desenvolvimento econômico da nova região portuária no tocante ao preço dos terrenos, destinação e mudança de perfil.

\section{Alguns aspectos acerca da construção do porto do Rio de Janeiro}

Antes, convém salientar a grande transformação pela qual passou a cidade do Rio de Janeiro no início do século xx, especificamente de 1903 a 1911, com a construção do novo porto e as reformas urbanas ocorridas na então Capital Federal, maior centro produtivo e financeiro do país. Urge lembrar que, desde a instauração da Corte Portuguesa no Rio de Janeiro em 1808, esta ci- 


\section{GRÁFICO 1. ENTRADAS E SAÍDAS DA NAVEGAÇÃO DE LONGO CURSO NO RIO DE JANEIRO.}

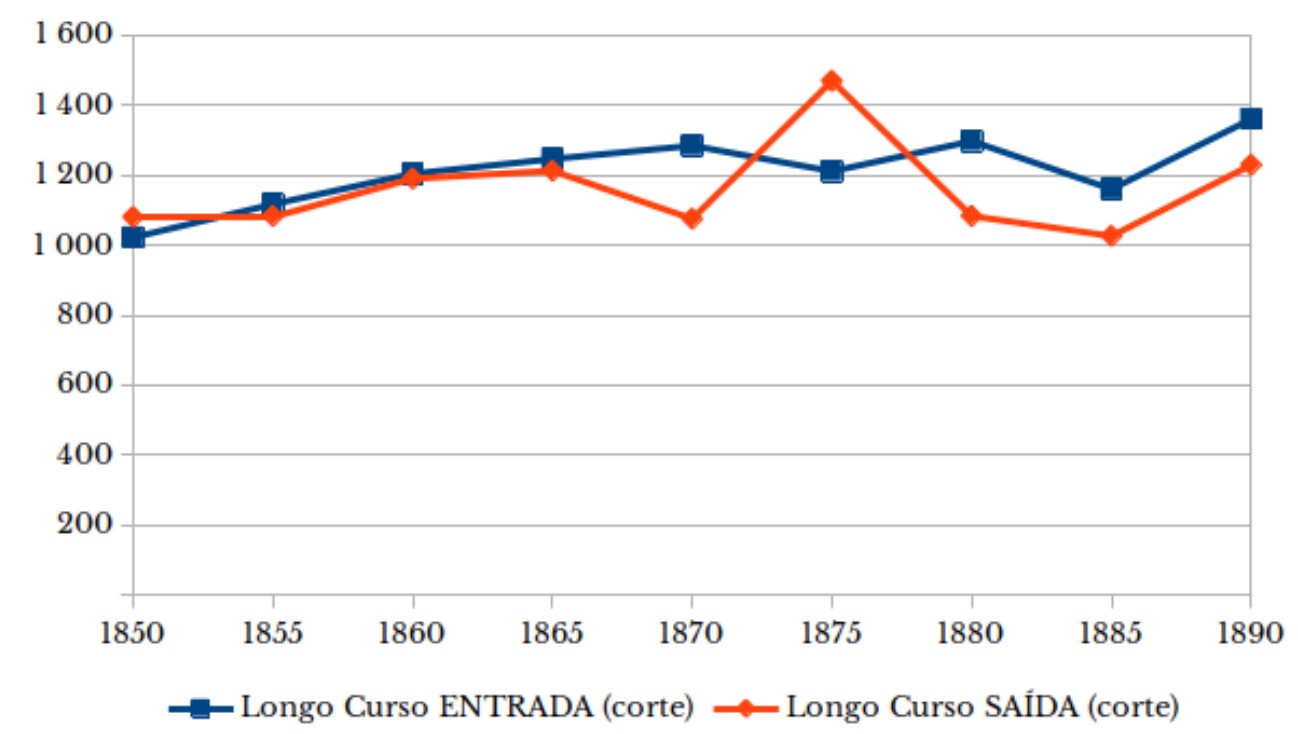

Fonte: Brasil. Ministério da Fazenda (1850-1890).

dade se tornou a principal porta de entrada e saída de mercadorias do país e principal Alfândega. Consequentemente, ocorreu um incremento na movimentação portuária nunca antes visto, especialmente após a grande expansão das exportações de café na década de 1850 (ver gráfico 1).

Sem nos delongarmos em demasia em dados do século xIx, podemos apontar o caráter internacionalista do porto do Rio de Janeiro (ver gráfico 2) e a sua proeminência como maior porto de importação e exportação, até a ascensão do Porto de Santos no início do século xx (Honorato, 2015).

Tal fato não deve surpreender, visto a cidade do Rio de Janeiro ser a sede administrativa do Brasil desde o período colonial, sediando a Alfândega Nacional e as principais empresas de navegação internacional, de bancos e de empresas de importação e exportação e que, desde os anos 1830 até o início do século xx, ser o epicentro da maior produção cafeeira do país (Honorato e Ribeiro, 2014).

Contudo, a sua estrutura operativa em termos portuários, continuava seguindo a lógica oriunda do período colonial com seus trapiches, armazéns, desembarque de mercadorias ao largo com transbordo por pequenas embarcações até o litoral, transporte de mercadorias por carroças e o seu conjunto de atividades sendo majoritariamente operada de forma manual. Além disso, inexistia qualquer organismo de gestão dos inúmeros interesses econômicos existentes.

Embora alguns melhoramentos tivessem ocorrido desde a segunda metade do século XIX (Mantuano, 2017), tais mudanças pouco alteraram a lógica do processo, ao contrário, reproduziram-na numa escala superior e, pouco a pouco, a inviabilizavam. O que garantia maior capacidade num primeiro momento, aprofundava as limitações daquele modelo e acirrava suas contradições com os diversos modais de transportes aos quais o porto estava ligado, resultando nos pronunciados gargalos de infraestrutura que tanto perturbavam os contemporâneos. Ao contrário do que acredita 


\section{GRÁFICO 2. NACIONALIDADE DAS COMPANHIAS DE VAPORES TRANSATLÂNTICOS NO PORTO DO RIO DE JANEIRO.}

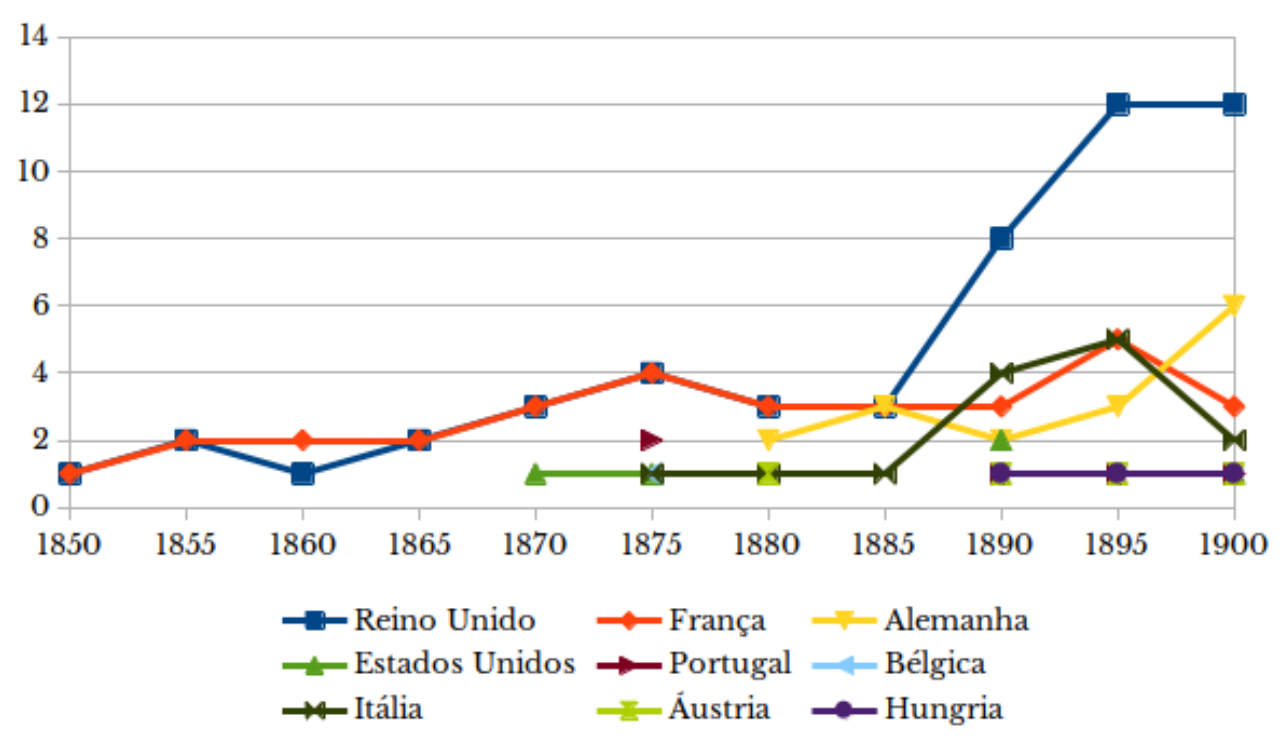

Fonte: Laemmert e Laemmert (1850-1900).

Velasco e Cruz (1998) -e não é só no caso do Rio de Janeiro, mas dos demais portos brasileiros, com exceção de Santos após 1888- foram feitos melhoramentos em estruturas antigas que não ultrapassavam a reprodução da velha lógica operativa, não se podendo caracterizá-lo como um porto capitalista.

Aliás, alguns analistas não conseguem perceber que, embora o local escolhido para a construção de um porto novo fosse o mesmo onde existiam secularmente os trapiches e armazéns, aquela mudança drástica do início do século não se tratava de um melhoramento portuário, mas de um novo complexo portuário que envolveu uma quantidade arbitrário de obras de engenharia portuária e hidráulica, incluindo grandes aterramentos e trabalhos de dragagem. Tal percepção é que nos distingue da visão de Velasco e Cruz (2016).

Desde a campanha eleitoral, o futuro presidente do Brasil, Francisco de Paula Rodrigues Alves, defendia como sua prioridade a construção de um porto novo, tal qual resolver os graves problemas de saúde pública que transformara a cidade do Rio de Janeiro, Capital Federal, numa cidade pestilenta nos dizeres da época, devido as grandes doenças que grassavam a sua população, como a febre amarela, por exemplo, e que impactavam também a movimentação portuária (Chalhoub, 1996). No seu discurso de posse, o recém-eleito presidente Rodrigues Alves é claro:

Os serviços do melhoramento do porto desta cidade [Rio de Janeiro] devem ser considerados como elementos da maior ponderação para esse emprehendimento grandioso [...]. Quando se consummarem, poder-se-há dizer que a capital da República libertou-se da maior difficuldade para seu completo saneamento e o operário bemdirá o trabalho que lhe fôr proporcionado para fim de tanta utilidade (Brasil, 1902). 
Visando resolver tais problemas, o governo Rodrigues Alves atuou em duas frentes. A primeira, uma grande intervenção urbana executada pela Prefeitura do Distrito Federal conhecida como Reforma Pereira Passos, que demoliu inúmeros imóveis e construiu a Avenida Central ligando o início do novo porto até a zona sul rasgando o velho centro da cidade. A segunda, construir um porto verdadeiramente moderno -capitalista- que possibilitasse ampliar as exportações e importações e melhorar os controles alfandegários do país.

Entre as obras propostas pelo Governo Federal está a que seria conhecida como a primeira seção do porto, que ia do Arsenal de Marinha até a Praia Formosa. Primeiramente, a área ganha sobre o mar para a construção do cais retilíneo era de 64 hectares e demandaria 5000000 de metros cúbicos de aterramentos entre a muralha do cais e a linha costeira original. Esta enorme área visava a construção de um cais retilíneo de 3500 metros com a média de nove metros de calado, o que permitia a atracação dos maiores navios da época na linha do cais. Com os trabalhos de dragagem, que deveriam totalizar $7037954 \mathrm{~m}^{3}$ de material retirado do leito submarino, o calado da meia maré entre o canal e o cais estava projetado, na média, em dez metros de profundidade ao longo de 250 metros extensão (Lisboa, 1922). Um exemplo do impacto desta medida foi a drástica diminuição da operação de carga/descarga ao largo e todo sistema de transbordo pelas pequenas embarcações.

A construção do porto novo se concretizou no que seria esta primeira seção, com 3355 metros de cais acostáveis. As dimensões das obras quanto a dragagem e aterramento foram bem superiores àquelas previstas, pois que foram dragados um total de $1687252500 \mathrm{~m}^{3}$ de material, sendo que parte desse total foi empregado no aterramento e outra parte foi retida do Morro do Senado, para o mesmo fim, $623905 \mathrm{~m}^{3}$ (Brasil, Relatório 1911).

Foram construídos 18 armazéns de 100 metros de comprimento por 35 metros de largura, totalizando cerca de $70000 \mathrm{~m}^{2}$ de área construída, entre estruturas permanentes e provisórias, contando com 100 metros de largura entre a linha do cais e o arruamento. Todos estes trabalhos se deram apenas entre o Arsenal de Marinha e a Praia Formosa, o que incluiu o término da canalização do Mangal de São Diogo, deixando inalterada a costa entre o canal e a Ponta do Caju.

\section{OS PROCESSOS ADMINISTRATIVOS E A CARTOGRAFIA COMO FONTES}

Para discutir a utilização dos processos administrativos e da cartografia existente na Superintendência do Patrimônio da União como fontes para o estudo dos portos e cidades sendo, neste caso, o do Rio de Janeiro, vamos levar em conta o processo administrativo, que Gasparini (2005) define como:

[...] em sentido prático, amplo, é o conjunto de medidas jurídicas e materiais praticadas com certa ordem de cronologia, necessárias ao registro dos atos da Administração Pública (...) registro de ato da Administração Pública, controle da conduta dos seus agentes e administrados, compatibilização do interesse público e privado, outorga de direitos, e solução de controvérsias entre Administração Pública e seus agentes ou administrados (p. 83). 
Neste caso, temos uma modalidade específica de processo administrativo que envolve a venda, cessão, aluguel ou permuta do direito de uso de imóveis da União, especialmente terrenos, a terceiros. De acordo com a legislação brasileira são da União os terrenos de marinhd ${ }^{2}$ e de sua designação respectivos aforamentos, os imóveis desapropriados ou adquiridos, os terrenos criados (solo criado) por ação do Poder Público ou ainda as chamadas terras devolutas. ${ }^{3}$

E, também, o Poder Público pode dispor de tais terrenos das seguintes formas principais: venda por hasta pública, normalmente leilão (na maioria das vezes, dá-se apenas por autorização do Congresso Nacional); cessão onerosa de uso em contrapartida a pagamento anual de foro; cessão para outro ente federativo; aluguel; cessão não onerosa e, finalmente, por permuta de imóveis com um ente privado. 4

O órgão incumbido de administrar e ceder os imóveis a terceiros é hoje a Superintendência do Patrimônio da União (SPU), vinculado ao Ministério da Economia do Brasil, embora tenha, ao longo do tempo, mudado de designação e de situação institucional, sem, contudo, alterar em síntese a sua função. Entre as competências da SPU sempre foram, entre outras, a incorporação e regularização do domínio dos bens; sua adequada destinação; controle e gestão dos recursos arrecadados das taxas decorrentes de cessão onerosa (foro, laudêmio, etc.); além do controle e da fiscalização dos imóveis públicos.

Aqui, nos deteremos nos processos administrativos que regularam a relação entre a Caixa Especial dos Portos e os interessados privados -em sua maioria empresas ou empresários- à busca da percepção dos interesses da Administração Pública e dos interessados e, bem como, as definições de contrapartida da negociação.

Embora não explicitado como objetivo na constituição da Caixa Especial dos Portos, através de outros documentos podemos pressupor o interesse do poder público na promoção de um novo ordenamento territorial para a região mais adequado ao apoio às atividades portuárias revolucionadas pela construção de um novo porto, ao desenvolvimento comercial e à industrialização.

Através da cartografia disponível, pode ser notado uma nítida transformação das lógicas de ordenamento territorial da região pré e pós intervenção. A imagem 1 demostra o desenho natural da costa na Região Portuária do Rio de Janeiro e a sua diferença para a brutal transformação para a construção do novo porto (ver figura 1).

Importante destacar que a cartografia histórica extrapola sua função restrita de retratar uma realidade passada. Ao contrário, aqui, dois aspectos nos motivam: primeiro, a possibilidade de buscar no histórico imobiliário das principais empresas da zona do cais do porto a possibilidade de refletir sobre a lógica de distribuição e arranjo espacial do setor empresarial na região antes das intervenções estruturais do poder público, via Caixa Especial dos Portos. Tal cenário nos permitiria uma reflexão mais aprofundada sobre as vantagens locacionais (acesso ao mar, possibilidade de navegação etc.), acesso aos recursos (disponibilidade de água, proximidade da mão de obra, etc.) e, principalmente, os acordos e parcerias, disputas políticas, tensões e complementaridades que circunscrevem e dão coerência a Comunidade Econômica Portuária.

Segundo, a necessidade de refletir sobre a cartografia não apenas como um instrumento de planejamento, mas como um instrumento ideológico que atuou ativamente como legitimador e construtor de outra lógica de ordenamento do espaço impresso pelo poder público, muito embora

\footnotetext{
${ }^{2}$ Entende-se os terrenos compreendidos num perímetro de 33 metros da preamar médio da orla marítima, das margens de rios e lagoas. Decreto 4.105, 22 de fevereiro de 1868. (Brasil. Colleção, 1868)

${ }^{3}$ São os terrenos em que inexiste proprietário conhecido e oficializado de forma mansa e pacífica.

${ }^{4}$ Devido aos objetivos deste artigo, não detalhamos as formas jurídicas de aquisição e cessão do patrimônio público.
} 
FIGURA 1. PLANTA DO PORTO DO RIO DE JANEIRO (1911).

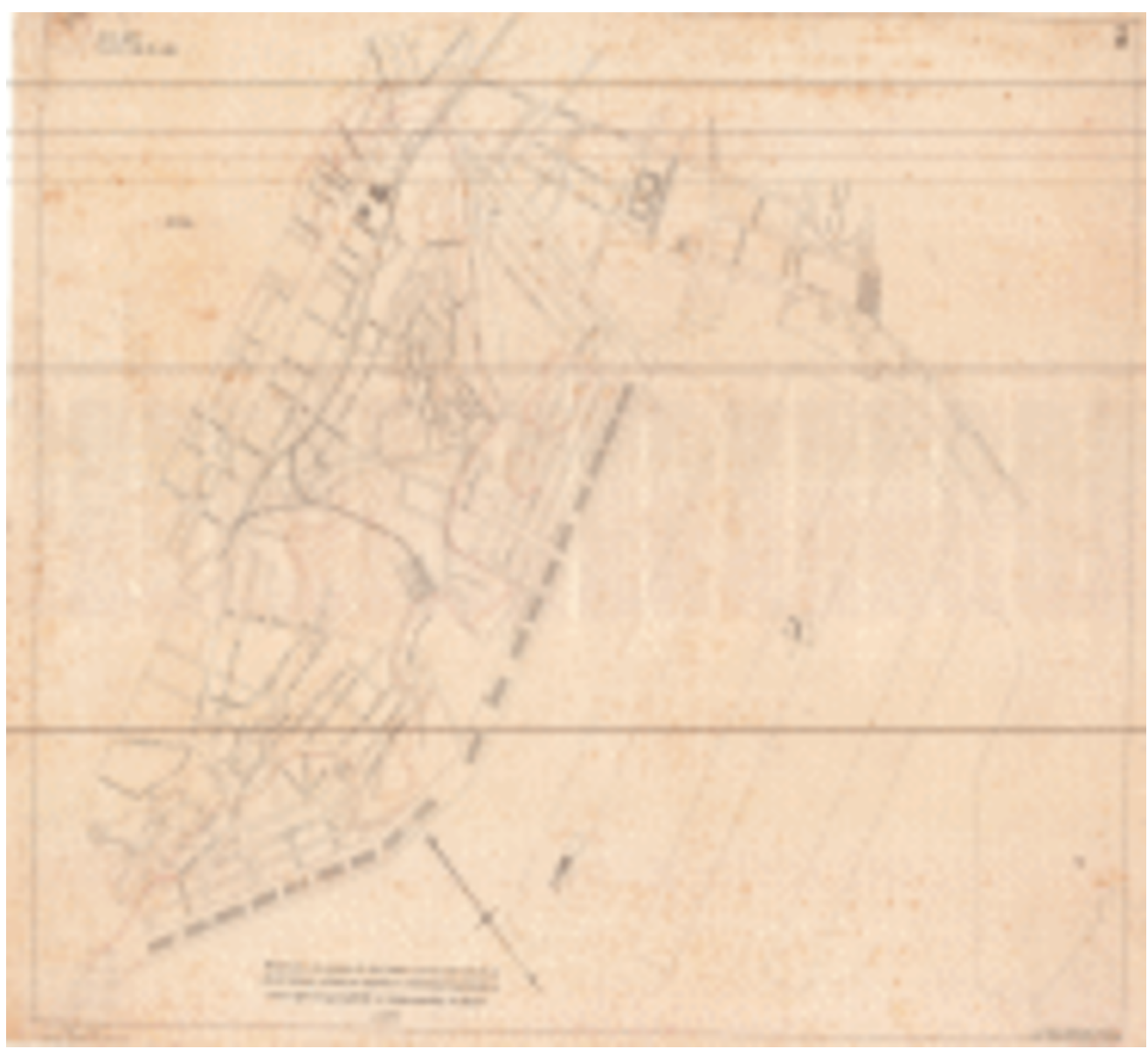

Fonte: Planta do Porto do Rio de Janeiro (1911) Brasil. Ministério do Planejamento, Desenvolvimento e Gestão (em diante MP). Mapoteca 1, gaveta 1, prancha 1, registro 96. Rio de Janeiro: Superintendência do Patrimônio da União (em diante SPU).

respondendo aos interesses de alguns setores sociais específicos. Já que é importante notar que não só a intervenção produz uma imensa área disponível para aquisição do setor privado, como também, produz uma lógica de ordenamento territorial pautado na especialização e funcionalização dos espaços, bem a semelhança de uma geografia industrial.

\section{A Caixa Especial dos Portos}

Para que fosse construído o novo porto, era necessário resolver preliminarmente duas ordens de problema: a questão das antigas concessões e os recursos financeiros para uma obra de tamanha envergadura. Ressalte-se que, desde meados do século XIx, a questão do financiamento de obras 
marítimas, hidráulicas e portuárias atormentava o Estado Imperial e frustrava agentes privados que se empenhavam em reunir capitais para dotar os portos brasileiros de melhoramentos significativos em suas operações ${ }^{5}$

O problema do financiamento das obras hidráulicas e portuárias no Brasil começou a se resolver a partir do debate que associava a premência das melhorias nos portos nacionais ao reconhecimento de que, sem o pesado recurso ao Tesouro Público, esses necessários investimentos não se efetivariam. Apenas nos estertores do Império, com o envio da lei $3314^{6}$ referente ao orçamento nacional é que as mais efetivas formas de garantias de juros foram admitidas (Brasil. Colleção, 1886). Contudo, somente seu impacto somente ocorreu no início do século xx quando a dupla definição de garantias de lucros combinadas à própria atuação direta da União tornou-se possível a transformação da lógica produtiva do porto do Rio de Janeiro.

A questão dos antigos concessionários -um dos entraves- pode ser equacionada pela recompra de antigas concessões. Através da lei 9577 o Congresso Nacional autorizou a Presidência da República a:

b) (...) para o fim a que se refere a disposição constante do presente numero [melhoramentos do porto do Rio de Janeiro], poderá o Governo entrar em accordo com as empresas concessionarias de melhoramentos do porto do Rio de Janeiro, cujos contractos estejam em pleno vigor, podendo fazer todas as despesas indispensaveis para a effectividade dos accordos que forem celebrados. (Brasil. Colleção, 1902)

Baseado nessa autorização legal, o Ministro da Fazenda adquiriu as concessões e benfeitorias da The Rio de Janeiro Harbour and Docks Company Ltd por 2.750:000\$00 ou 229166.67 libras esterlinas 8 e, de compra e venda de concessões, terrenos e demais benfeitorias das Empreza Industrial de Melhoramentos do Brazil, a Companhia União dos Trapiches, a Companhia Docas Nacionais e Empreza de Arrazamento do Morro do Castelo no valor total de 21.380:000\$00 ou 1781666.67 libras esterlinas ao câmbio de 1903, num total de 2010833.34 libras esterlinas ou seja o equivalente a 1/4 do empréstimo contraído em Londres (Brasil. Colleção, 1903).

Com tal providência, o Governo já não tinha mais nenhum obstáculo jurídico oriundo de antigas concessões que inviabilizasse juridicamente o início das obras, exceto por falta de capitais próprios. Para que tal operação fosse realizada o Ministro da Fazenda foi autorizado, através do decreto 4.8399 a: "contractar com os banqueiros N. M. Rothschild and Sons, de Londres, um emprestimo de oito e meio milhões sterlinos [8 500000 libras esterlinas] capital nominal, ao preço de noventa libras esterlinas [90 libras esterlinas] por cem e juros de cinco por cento [5\%] ao anno, destinado ás obras de melhoramento do porto desta Capital e outras complementares" (Brasil. Colleção, 1903).

\footnotetext{
${ }^{5}$ Existem vários estudos sobre o engenheiro André Rebouças, destacamos como um dos mais recentes o de Trindade (2011).

${ }^{6} 16$ de outubro de 1886 , em Brasil. Colleção (1886).

730 de dezembro de 1902, em Brasil. Colleção (1902).

${ }^{8}$ Escritura de Compra e Venda da concessão para obras do Porto do Rio de Janeiro que a Fazenda Federal da República dos Estados Unidos do Brazil faz a The Rio de Janeiro Harbour and Docks Company Limited. Cartório do $1^{\circ}$ Ofício da Capital Federal de 10 de junio e 30 de junio (1903). MP. sPU.

${ }^{9} 18$ de maio de 1903, em Brasil. Colleção (1903).
} 
Através do decreto $4.859^{10}$ foi estabelecido um regime especial para a execução das obras de melhoramento de portos com a emissão de títulos públicos, renda dos propriedades desapropriadas, construídas ou aforadas, $2 \%$ ouro sobre o valor das importações (embora a taxação das rendas de cais, armazéns e demais serviços portuários fosse garantida desde a década de 1860). Dois anos depois, em 1905, devido às pressões políticas dos donos de trapiches, armazéns e grandes importadores, foi decretada a isenção da taxa para quem não utilizasse os serviços do novo porto.

Finalmente, pelo decreto 4.96911 foram aprovados os planos, plantas e orçamentos para a execução das obras do porto do Rio de Janeiro, declarando desapropriados os prédios e terrenos necessários e criada uma Caixa Especial para executar estes serviços (Brasil. Colleção, 1903).

Funcionando como um grande fundo público a Caixa Especial dos Portos deveria não só controlar as despesas da obra como administrar os recursos provenientes do empréstimo contraído em Londres, as receitas dos novos tributos e vender os terrenos a serem desapropriados e os novos terrenos acrescidos decorrentes dos aterramentos sobre o mar ou desmonte de antigos morros, que passariam a compor o seu patrimônio, visando o desenvolvimento econômico da região e sustentabilidade econômica do projeto.

Nesse sentido, o governo emitiu títulos federais no montante de 17.300:000\$000 (857 070 libras esterlinas) visando complementar os recursos não só para as obras do porto, mas para as reformas urbanas complementares. Em 1903 o governo criou a taxa de 1.5\% ouro das importações no porto do Rio e pelo mesmo decreto abriu crédito de 300:000\$000 (14 862 libras esterlinas) buscando garantir o pagamento do empréstimo feito em Londres.

O Governo Federal acreditava que com as novas receitas oriundas dos tributos, da venda de imóveis e da expansão econômica, conseguiria, não só pagar o referido empréstimo, como ter recursos para a consecução das obras da chamada segunda seção que iria do Canal do Mangue até a Ponta do Caju, o que somente ocorreu três décadas depois. Posteriormente, a Caixa Especial dos Portos passou a operar como fundo para a execução de obras em outros portos no Brasil, com aportes de capital específicos.

Doze anos depois, pela lei 3.070 12 todo o patrimônio da Caixa Especial dos Portos foi transferido para a Diretoria do Patrimônio do Ministério da Fazenda, deixando aquela de existir formalmente. Em realidade, o mecanismo de Caixa Especial utilizado para vários fins pelos governos anteriores foi considerado ultrapassado e as suas funções, recursos, patrimônio, créditos e débitos passaram a ser diretamente administrados pelo Ministério da Fazenda. No caso da Caixa Especial dos Portos, o patrimônio imobiliário passou para a Diretoria do Patrimônio da União e as receitas para o Tesouro.

Interessa-nos explorar exatamente a questão dos terrenos sub controle da Caixa Especial dos Portos resultantes da construção do porto do Rio de Janeiro, que incluíam os terrenos desapropriados para a execução das obras, inclusive do morro do Senado de onde se retiraria o material de aterramento, os aterramentos (solo criado) e os acrescidos aos chamados terrenos de marinha.

Somente os terrenos do Cais do Porto surgidos com os aterramentos foram divididos em 51 quadras, perfazendo um total de 671 lotes caracterizando uma área de $318749.57 \mathrm{~m}^{2}$ que deveriam ser colocados à venda pela Caixa aos empresários interessados em investir no novo território que seria construído. Ao longo do período de construção compreendido entre o 1903 e 1910, a

\footnotetext{
${ }^{10} 8$ de junho de 1903, em Brasil. Colleção (1903).

${ }^{11} 18$ de setembro de 1903, em Brasil. Colleção (1903).

1231 de dezembro de 1915, em Brasil. Colleção (1915).
} 
Caixa Especial dos Portos buscou reservar ou vender os terrenos que iam sendo liberados com o avanço das obras, incluindo neste caso os terrenos surgidos pela demolição do antigo Morro do Senado, que gerou o material para o aterramento necessário para a construção do porto.

A Caixa Especial dos Portos conforme previsto na legislação, deveria também financiar a reforma dos demais portos da União, embora a sua prioridade fosse o Porto do Rio de Janeiro. A execução das obras caberia a Inspetoria Geral dos Portos a fiscalização das obras portuárias por concessão ou por empreitada, como no caso do porto do Rio de Janeiro após efetuar a contratação da gabaritada firma inglesa C. H. Walter \& C. Ltd., que recebeu 4500000 de libras esterlinas pelos seus serviços.

\section{A destinação dos terrenos criados com a CONSTRUÇÃo do Porto}

A lógica espacial-produtiva do porto do Rio de Janeiro sofreu uma ruptura com a construção do espaço urbano capitalista na Região Portuária. As empresas e os agentes que antes tinham acesso ao mar pelo privilégio dos aforamentos de terras de marinha, ou através de concessões que abrangessem parcelas dessas terras, perderam esta prerrogativa e tiveram de encontrar novos espaços para reestabelecer seu negócio. Algumas decidiram manter a lógica precedente e procuraram ocupar, mais intensamente, as praias de São Cristovão e a Ponta do Caju, fora do novo porto. Outras optaram por ter acesso aos lotes dos terrenos acrescidos aos de marinha, ou seja, criados com os aterramentos, para ali construir armazéns numa nova forma de produzir o espaço portuário.

Para uma análise das empresas instaladas anteriormente às obras de construção do novo porto e comparar com a situação do período seguinte (ver tabela 1).

Em primeiro lugar, havia 42 empresas operando formal e legalmente na zona imediatamente costeira, ou mais próxima às praias e ao Canal do Mangue. Bom ressaltar que são empresas com acesso franco ou facilitado ao mar ou ao mangue que desembocava no mar. Deste montante, 24 são trapiches, cinco são de armazenagem, cinco são predominantemente de construção e repa-

ros navais, dois de transportes urbanos, três de alimentos com armazenagem e três de navegação interna. Ou seja, o predomínio dos antigos trapiches que operavam o porto do tipo antigo. 


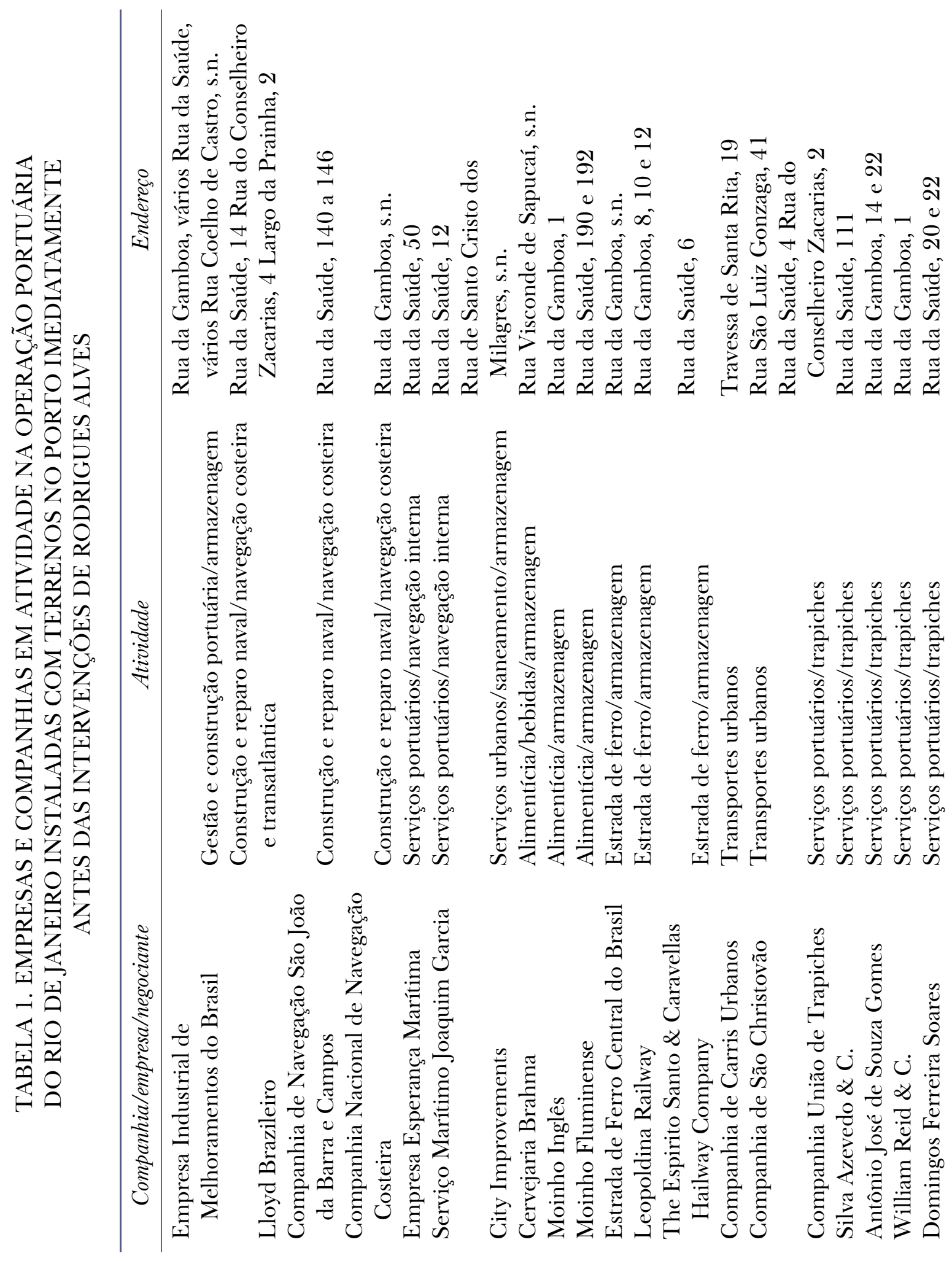



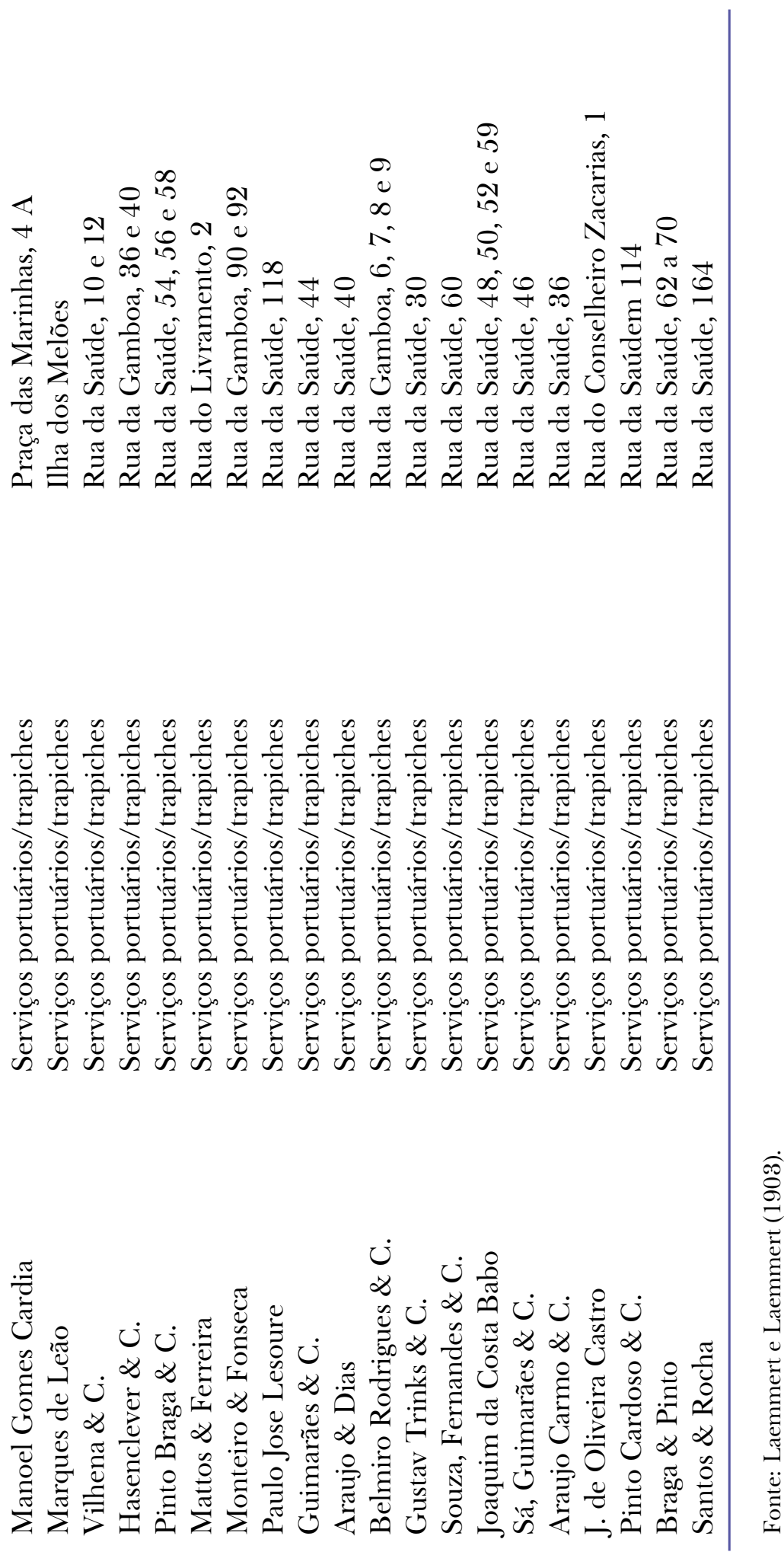


\section{TABELA 2. EMPRESAS E COMPANHIAS EM ATIVIDADE NA OPERAÇÃO PORTUÁRIA DO RIO DE JANEIRO INSTALADAS COM TERRENOS NO PORTO IMEDIATAMENTE ANTES DAS INTERVENÇÕES DE RODRIGUES ALVES E QUE PERMANECERAM APÓS AS REFORMAS (1911)}

\begin{tabular}{ll}
\hline \multicolumn{1}{c}{ Companhia/empresa } & \multicolumn{1}{c}{ Atividade } \\
\hline & Construção e reparo naval/navegação costeira \\
Lloyd Brazileiro & e transatlântica \\
Companhia Nacional de Navegação Costeira & Construção e reparo naval/navegação costeira \\
City Improvements & Serviços urbanos/saneamento/armazenagem \\
Cervejaria Brahma & Alimentícia/bebidas/armazenagem \\
Moinho Inglês & Alimentícia/armazenagem \\
Moinho Fluminense & Alimentícia/armazenagem \\
Estrada de Ferro Central do Brasil & Estrada de ferro/armazenagem \\
Leopoldina Railway & Estrada de ferro/armazenagem \\
Companhia União de Trapiches & Armazenagem \\
\hline
\end{tabular}

Fonte: Laemmert e Laemmert (1911).

Porém, ao analisarmos o arranjo espacial destas empresas, podemos notar de forma geral lógicas de distribuição que vão além da proximidade costeira, obedecendo aos critérios de: proximidade dos bolsões de habitação popular, das linhas ferroviárias e de transportes urbanos sobre trilhos; concentração nos acessos da região portuária ao centro comercial, financeiro e político da cidade; além de estarem localizadas nas disputadas enseadas naturalmente abrigadas e de fronte aos melhores ancoradouros da cidade.

Como demonstramos em outro trabalho (Honorato e Mantuano, 2015), os agentes múltiplos do porto pré-capitalista buscavam monopolizar uma linha de serviço, oferecendo todo o necessário para o translado, transbordo, carga, descarga, armazenagem, acondicionamento, despacho e comércio das mercadorias que ali eram negociadas, além de monopolizaram partes do litoral. Assim, além de avultar suas rendas e ver crescer as margens de lucros, se autonomizavam politicamente de potenciais competidores, atraindo para si, outros negociantes menores ou trabalhadores avulsos como satélites ou dependentes de suas atividades (ver figuras 2 e 3).

Com a construção do novo porto, das 42 empresas existentes antes da obra, continuaram apenas nove, exatamente as maiores existentes na região, sendo cinco classicamente industriais (ver tabela 2). Os 24 trapiches existentes foram retirados da orla marítima para a construção do novo porto. Embora boa parte deles tenha migrado para São Cristovão e para o Caju, pelo menos um desses proprietários de trapiches decidiu apostar nos terrenos criados pela obra do porto: a Companhia União de Trapiches - ainda pouco pesquisada- deixou de ser uma empresa que oferecida grande variedade de serviços portuários e passou a desempenhar, única e exclusivamente, o papel de armazém no porto moderno.

Após a conclusão da primeira seção do porto do Rio de Janeiro, novas empresas se instalaram (ver tabela 3). Excetuando-se a Lidgerwood -indústria metalmecânica que produzia máquinas e equipamentos-, o Banco do Brasil, a Companhia Brasileira de Imóveis e Construções, a Fundição Oswaldo Cruz e cinco de armazenagem para importação e exportação, as 13 demais eram 


\section{FIGURA 2. DISTRIBUIÇÃO ESPACIAL DOS SERVIÇOS PORTUÁRIOS NA ZONA DO CAIS DO PORTO ANTES DA SUA CONSTRUÇÃO (1903)}

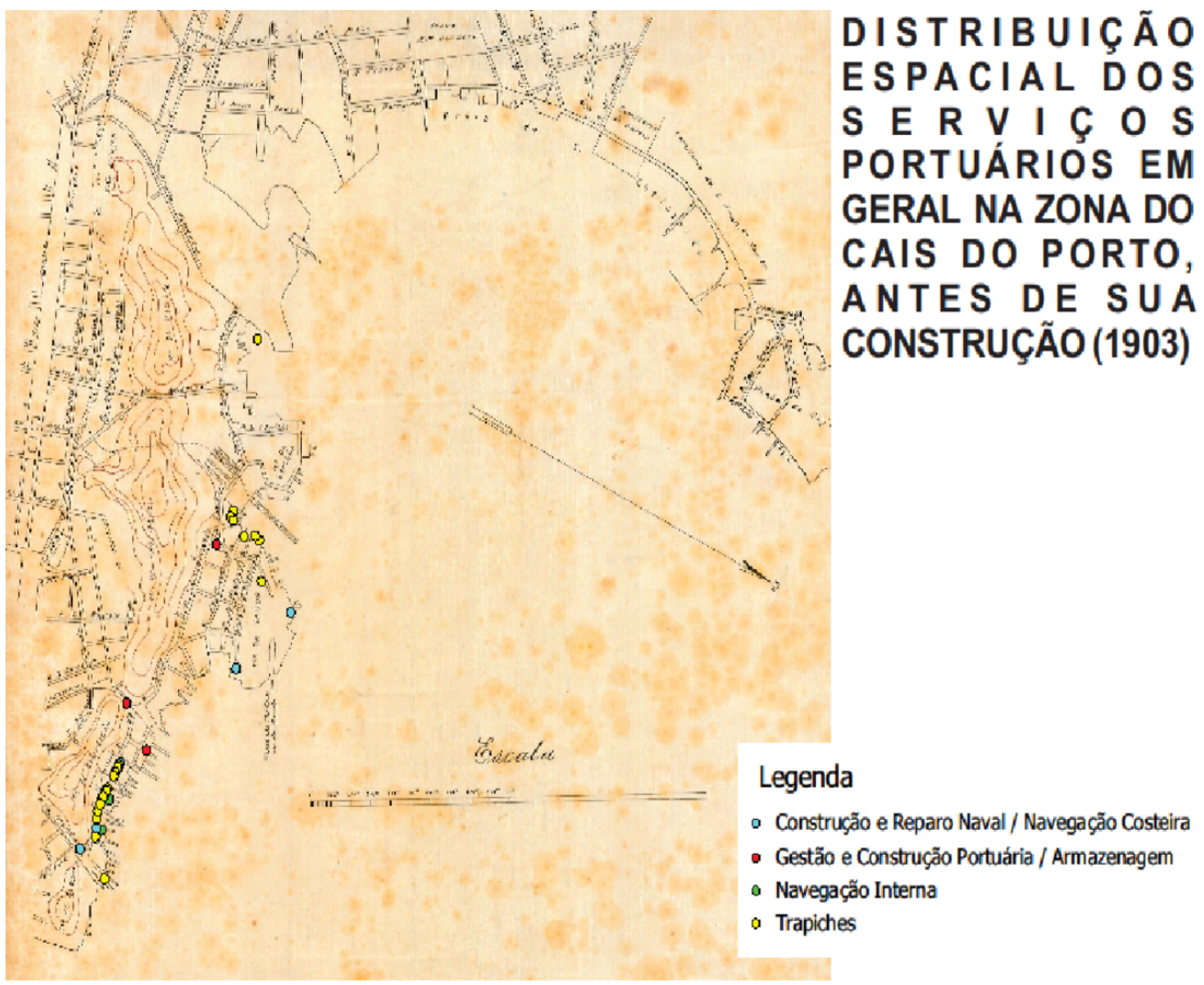

Fonte: Brasil. MP. Mapoteca 1, Gaveta 1, Prancha 1, Registro 48. sPu.

somente de armazenagem. Ressalte-se que neste momento, muitos agentes individuais, ainda não identificado com nenhuma empresa, adquiriam o direito de explorar e construir nos terrenos da Caixa Especial dos Portos.

Uma outra lógica de ordenamento territorial para a região fora expressa (ver figura 4).

Quando observamos algumas empresas que adquiriram os direitos de utilizar terrenos oriundos da Caixa Especial dos Portos, pagando foro anual para tal, entre 1912 e 1937, podemos perceber que, além de seis de armazenagem, quatro de importação e exportação, dois de ordem religiosa, as nove restantes são caracteristicamente de transformação.

Comparando tais informações com as constantes nas tabelas 1, 2 y 3 , podemos perceber que todas as empresas de pequeno e médio porte que anteriormente ocupavam terrenos com acesso ao mar -especialmente os trapiches e armazéns - foram retiradas, ficando apenas as grandes empresas que tinham propriedades não impactadas pelas obras.

De outra forma, as novas empresas instaladas entre 1911 (data de conclusão das obras) e 1937 (os dados disponíveis) eram empresas de grande porte e diretamente relacionada à atividades portuária e industrial, em que pese a cessão para instituições religiosas, públicas (Banco do Brasil e Universidade do Brasil) e sindicais. 
TABELA 3. EMPRESAS E COMPANHIAS EM ATIVIDADE NA OPERAÇÃO PORTUÁRIA DO RIO DE JANEIRO (EMBARQUE, DESEMBARQUE, ARMAZENAGEM, DEPÓSITO, GUARDA, TRANSPORTES MARÍTIMOS E TERRESTRES) IINSTALADAS COM TERRENOS NO PORTO IMEDIATAMENTE APÓS AS INTERVENÇÕES DE RODRIGUES ALVES (1911).

\begin{tabular}{ll}
\hline \multicolumn{1}{c}{ Companhia/empresa/negociante/instituição } & \multicolumn{1}{c}{ Atividade } \\
\hline Compagine du Port de Rio de Janeiro & Gestão portuária/armazenagem \\
Empresa de Armazéns Frigoríficos & Armazenagem \\
Hime \& C. & Armazenagem/importação e exportação \\
The Caloric & Armazenagem/importação e exportação \\
International Harvester Export Company & Armazenagem/importação e exportação \\
Hermann, Stoltz \& C. & Armazenagem/importação e exportação \\
Banco do Brasil & Banco \\
Companhia Brasileira de Imóveis e Construções & Engenharia e construções \\
Lidgerwood & Metalmecânica \\
Fundição Oswaldo Cruz & Metalúrgica \\
Alberto Junqueira & Armazenagem \\
Alfredo Américo de Sousa Rangel & Armazenagem \\
Raymundo de Castro Maia & Armazenagem \\
Luiz da Rocha Miranda & Armazenagem \\
João Proença & Armazenagem \\
Estado de Minas Gerais & Armazenagem \\
Companhia Brasileira de Imóveis e Construções & Armazenagem/construtora \\
Leon Israel & Armazenagem/importação e exportação \\
Joaquim José Palhares Sobrinho & Armazenagem \\
Armando Monteiro & Armazenagem \\
Antônio Fernandes dos Santos & Armazenagem \\
Is.n.ard \& C. & Armazenagem \\
\hline
\end{tabular}

Fonte: Laemmert e Laemmer (1911). 


\section{FIGURA 3. DISTRIBUIÇÃO ESPACIAL DAS EMPRESAS DE INFRAESTRUCTURA E SETOR ALIMENTÍCIO NO CAIS DO PORTO ANTES DA SUA CONSTRUÇÃO (1903)}

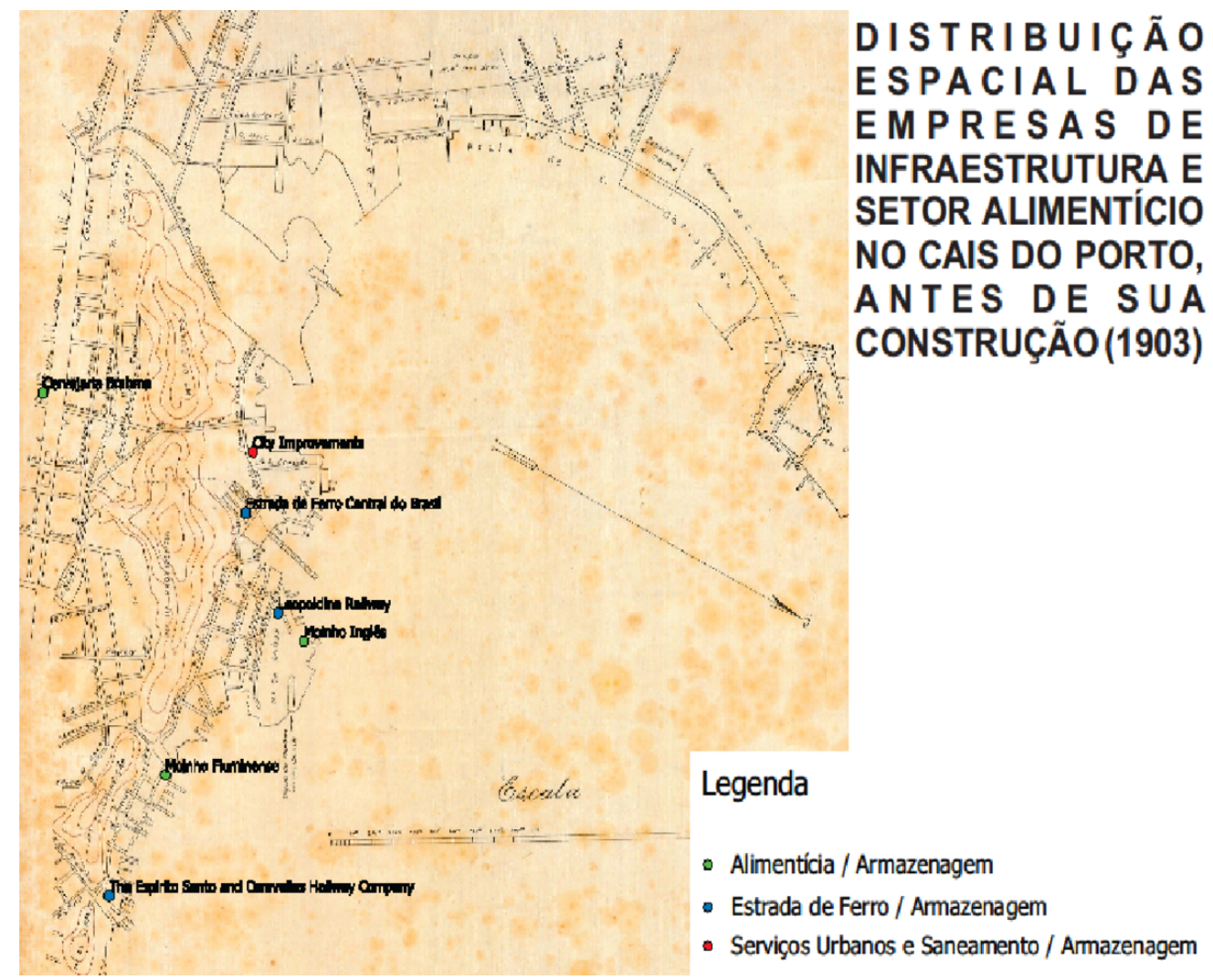

Fonte: Planta da Zona do Cais do Porto Antes da Sua Construção (1903) Brasil. MP. Mapoteca 1, Gaveta 1, Prancha 1, Registro 48. SPU.

Gostaríamos de registrar a compra de um terreno pelo governo do Estado de Minas Gerais. Não se tratava de uma operação normal, visto que a legislação brasileira garantia a transferência sem ônus entre os entes federativos. Contudo, embora o processo seja omisso, podemos supor, pela localização do imóvel e pelas características da operação, que se tratava de um imóvel visando a construção de um armazém para atender os exportadores de café daquele estado.

Infelizmente, a documentação até agora compulsada não nos permitiu ter informações precisas acerca dos imóveis desapropriados para a execução das obras e que foram incorporados a Caixa Especial dos Portos. Apenas, o volume de recurso dedicados a este fim aponta em 1910 um total de 1.120:678\$200 (75 458 libras esterlinas) já realizadas e a previsão de 1.133:352\$000 (76 312 libras esterlinas) com novas desapropriações (Brasil. Relatório, 1910).

Ao analisarmos os dados dos leilões ocorridos entre 4 de agosto e 12 de novembro de 1910 , podemos extrair várias observações. Primeiramente, que foram arrematadas $9.359 \mathrm{~m}^{2}$ gerando um total de 471:540\$000 (33 832 libras esterlinas) para a CEP. Em segundo lugar, o valor do metro quadrado de 30\$000 (primeiro leilão) e de 50\$000 (segundo leilão) já demonstra uma valorização do valor do terreno com o avanço da conclusão da obra, embora ainda muito longe 


\section{FIGURA 4. PLANTA GERAL DOS TERRENOS PERTENCENTES À CAIXA ESPECIAL DO PORTO DO RIO DE JANEIRO (1912)}

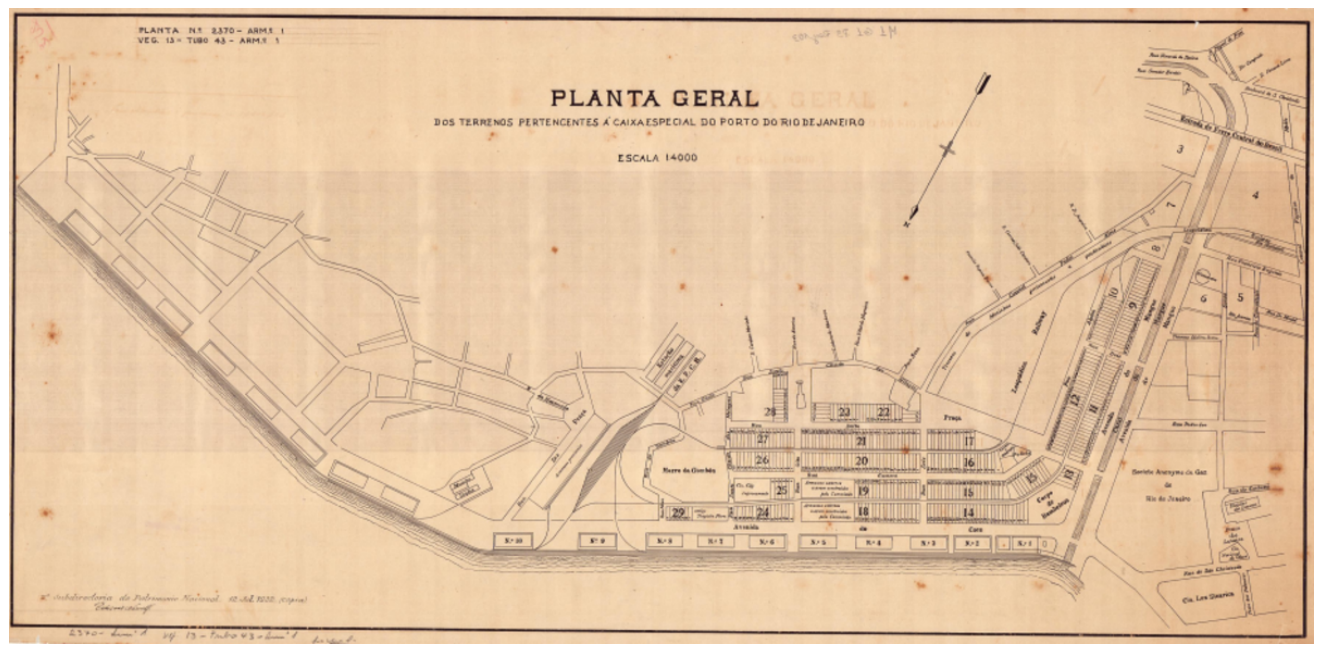

Fonte: Brasil. MP. Mapoteca 1, Gaveta 1, Prancha 1, Registro 48. SP.

daquele apontado na fonte de 1927. Logo, ou a informação da fonte reproduzida não é fidedigna ou ocorreu uma valorização de 10 vezes o valor ao longo de 17 anos, o que somente poderá ser avaliado com o avanço da pesquisa.

Um pouco antes, em 23 de fevereiro de 1910, através da venda por leilão prévio pela Caixa Especial dos Portos ao Dr. Jose Augusto Prestes, um terreno de $12000 \mathrm{~m}^{2}$ foi adquirido por um total de 480:000\$000 (30 160 libras esterlinas), pagos à vista. Dois anos depois, em 1912, este imóvel foi incorporado pelo comprador à Empreza de Armazéns Frigoríficos com o valor do metro quarado atingindo $40 \$ 00013$

Já no ano de 1916, os vários leilões realizados apesar da oscilação no preço dos terrenos provenientes da sua localização na linha do cais ou próximo a linha férrea ou apontam uma valorização ou outra vantagem comparativa, oscilando entre 50\$000 e 118\$000 o preço do metro quadrado (ver tabela 4).

\footnotetext{
${ }^{13}$ Aviso Ministerial 492, 11 de dezembro de 1911; Decreto 9.078, 3 de novembro de 1911; DOU, 2 de junho de 1912, em Brasil, Colleção $(1911,1912)$
} 


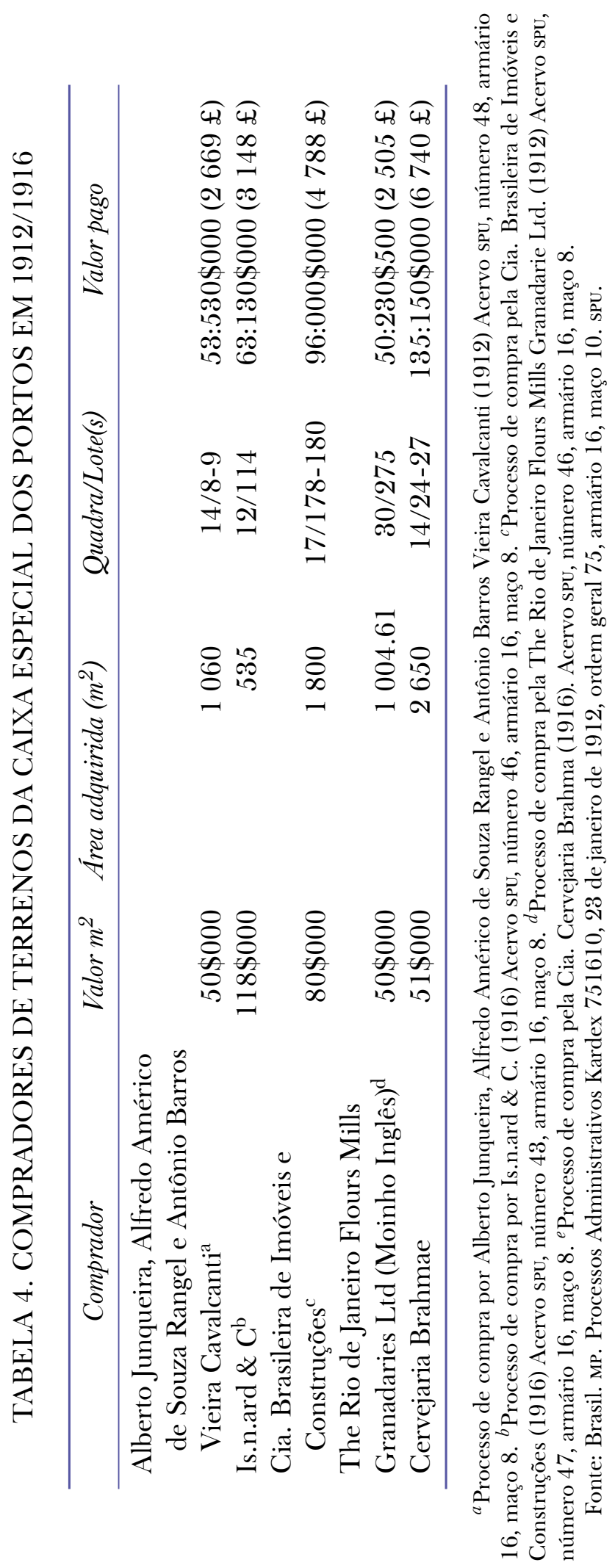




\section{Conclusões}

Ao longo deste artigo buscamos explorar o caso da construção do porto do Rio de Janeiro e de uma nova comunidade econômica portuária nos territórios por ele criados, como primeiro desdobramento do Projeto Acervo Documental das SPU.

Pelo exposto, pode-se perceber a estratégia do governo brasileiro para viabilizar a própria construção do porto e a ocupação dos terrenos acrescidos pela obra buscando atender aos interesses dos grandes grupos empresariais nacionais e estrangeiros existentes antes e após a reforma do porto do Rio de Janeiro. Tal preocupação deve-se ao fato de que o porto do Rio de Janeiro, localizado na Capital Federal, deveria ser construído visando à melhor integração do Brasil na rede marítima global e, devido a isso, ampliar as exportações de comodities, especialmente o café, e de principal porto de recepção e paragem das grandes companhias marítimas internacionais.

Finalmente, acreditamos que, pelo ineditismo do tema, pelas fontes apresentadas e pela metodologia apresentada, nos possibilite avançarmos na pesquisa e estimular outros pesquisadores a seguir na mesma senda.

\section{LISTA DE REFERENCIAS}

Bird, J. (1963). The Major Seaports of the Unites Kingdom. London: Hutchison.

Brasil (1902). Manifesto Inaugural de Francisco de Paula Rodrigues Alves, Presidente Eleito para o Quadriennio de 1902 a 1906. Recuperado de http://www.biblioteca.presidencia.gov.br/presidencia/ presidencia/ex-presidentes/rodrigues-alves

Brasil. Ministério de Fazenda (1850). Proposta e Relatório. Rio de Janeiro: Tipografía Nacional.

Castillo, D. (2015). Puerto de Dakar, puerta de África occidental: una historia económica de Senegal (1857-1957). Santa Cruz de Tenerife: VeredaLibros.

Chalhoub, S. (1996). Cidade febril: Cortiços e epidemias na corte imperial. São Paulo: Companhia das Letras.

García, M. R. e Rey, O. (orgs.). (2016). Fronteras de agua: las ciudades portuarias y su universo cultural (siglos XIV-XXI). Santiago de Compostela: Universidade de Santiago de Compostela.

Gasparini, D. (2005). Direito Administrativo. São Paulo: Saraiva.

Ginsburg, C. (1990). Sinais: raízes de um paradigma indiciário. Em C. Ginsburg (org.), Mitos, emblemas e sinais: morfologia e história. São Paulo: Companhia das Letras.

Guimerá, A. e Romero, D. (orgs.). (1996). Puertos y sistemas portuarios (siglos XVI-XX). Madrid: Ministerio de Fomento.

Hayuth, Y. (1982). The Ports-Urban Interface An Area in Transition. Area, 14(3).

Honorato, C. (2015). O polvo e o porto: a Companhia Docas de Santos (1888-1914). Curitiba: Prismas.

Honorato, C. (2018). Revisitando um velho tema: as reformas urbanas do Rio de Janeiro no início do século xx (1902/1910). Em P. Campos e P. Brandão (orgs.), Dimensões do empresariado brasileiro: história, organizações e ação política. Rio de Janeiro: Consequência.

Honorato, C. e Mantuano, T. (2015). O que era o trapiche? O porto e a cidade do Rio de Janeiro no século XIX. Acervo, 28, pp. 144-158.

Honorato, C. e Mantuano, T. (2016). A economia da região portuária do Rio de Janeiro (18701900). Nuevo mundo mundos nuevos. DoI: 10.4000/nuevomundo.69968 
Honorato, C. e Ribeiro, L. C. (2014). The emergence of Santos as a coffee port 1869-1914. Em M. Suárez (org.), Atlantic ports and the first globalisation c. 1850-1930. England: Palgrave MacMillan.

Hoyle, B. S. (1997). Cities and ports: concepts and issues. Vegueta, 3.

Hoyle, B. S. e Pinder, D. (orgs.). (1992). European port cities in transition. London: Belhaven Press.

Laemmert, E. e Laemmert, H. (1850-1900, 1903, 1911). Almanack Laemmert, Almanak Administrativo, Mercantil e Industrial da Corte e Provincia do Rio de Janeiro. Rio de Janeiro: Tipografia Laemmert.

Lisboa, A. (1992). Portos do Brasil. Rio de Janeiro: O Norte.

Mantuano, T. V. (2017). Comenadador Antônio Martins Lage: entre a navegação e a operação portuária no século XI (Mestrado). Universidade Federal Fluminense, Niterói.

Suárez-Bosa, M. (2014). Atlantic ports and the first globalisation c. 1850-1930. England: Palgrave MacMillan.

Trindade, A. D. (2011). André Rebouças: Um engenheiro do Império. São Paulo: Hucitec/FAPESP.

Velasco e Cruz, M. C. (1998). Virando o jogo: estivadores e carregadores no Rio de Janeiro da Primeira República (Tese de Doutoramento). PPGS-USP, São Paulo.

Velasco e Cruz, M. C. (2016). O cais do Porto no Crivo da política: a burguesia mercantil e a modernização portuária no Rio de Janeiro da Primeira República. Em M. C. Velasco e Cruz, M. G. A. Leal e J. R. M. Pinho (orgs.), Histórias e espaços portuários. Salvador e outros portos (pp. 289-331). Salvador: EDUFBA. 